\title{
PENENTUAN HARGA POKOK PRODUKSI PADA PT PERKEBUNAN NUSANTARA XIV (PERSERO) PABRIK GULA TAKALAR
}

\author{
Andi Mulia Saleh \\ (STIE Tri Dharma Nusantara) \\ andimulya987@gmail.com
}

\begin{abstract}
ABSTRAK
Penelitian ini bertujuan untuk mengetahui penentuan harga pokok produksi pada PT. Perkebunan Nusantara XIV (Persero) Pabrik Gula Takalar telah menggunakan dengan penentuan harga pokok produksi metode full costing Penelitian ini menggunakan data kualitatif dan kuantitatif, serta sumber data yaitu data primer dan data sekunder. Metode analisis yang digunakan adalah analisis deskriptif kualitatif. Berdasarkan hasil analisis penelitian diketahui bahwa penentuan harga pokok produksi yang digunakan PT. Perkebunan Nusantara XIV (Persero) Pabrik Gula Takalar, telah menggunakan metode full costing.
\end{abstract}

Keywords: Harga pokok produksi, full costing.

\section{PENDAHULUAN}

Perusahaan manufaktur adalah perusahaan yang mengolah bahan baku menjadi barang setengah jadi atau barang jadi dengan berbagai macam proses produksi untuk dijual kepada pelanggan. Salah satu tujuan yang penting untuk dicapai oleh perusahaan manufaktur adalah pencapaian laba maksimal. Selain laba, perusahaan manufaktur juga harus meningkatkan mutu dan kualitas produk untuk menghadapi para pesaingnya pada pangsa pasar produk manufaktur, serta dapat memberikan manfaat bagi masyarakat.

Laba dapat dicapai apabila perusahaan harus dapat melakukan kegiatan penjualan. "Pada perusahaan manufaktur sebelum menghitung harga pokok penjualan, terlebih dahulu menghitung harga pokok produksi. Harga jual suatu produk ditentukan dari harga pokok produksi, jika perhitungan harga pokok produksi tidak tepat maka akan mempengaruhi penentuan harga jual produk yang tidak tepat juga. Harga pokok produksi 
sendiri terdiri dari beberapa unsur, yaitu biaya bahan baku, biaya tenaga kerja langsung, dan biaya overhead pabrik. Harga pokok produksi menurut metode full costing memperhitungkan semua unsur biaya produksi ke dalam harga pokok produksi yang terdiri dari biaya bahan baku, biaya tenaga kerja langsung dan biaya overhead pabrik, baik yang berperilaku variabel maupun tetap.

Banyak manfaat harga pokok produksi yang dibutuhkan oleh pihak intern maupun pihak ekstern dari perusahaan sehubungan dengan penentuan laba perusahaan. Harga pokok produksi sangat berpengaruh dalam perhitungan laba rugi perusahaan, apabila perusahaan kurang teliti atau salah dalam menentukan harga pokok produksinya, dapat mengakibatkan kesalahan penentuan laba rugi yang diperoleh perusahaan. Maka diperlukan informasi harga pokok produksi untuk pengambilan keputusan. Menetapkan harga jual yang tidak terlalu tinggi atau rendah, agar harga jual yang dihasilkan dapat bersaing dengan perusahaan pada pangsa pasar produk manufaktur, serta memberikan laba sesuai dengan diharapkan dari produk yang dihasilkan.

Berdasarkan uraian yang telah dijelaskan pada latar belakang, maka rumusan masalah yang akan dibahas dalam penelitian ini adalah "Apakah penentuan harga pokok produksi pada PT. Perkebunan Nusantara XIV (Persero) Pabrik Gula Takalar menggunakan penentuan harga pokok produksi metode full costing?

\section{TELAAH LITERATUR DAN PENGEMBANGAN HIPOTESIS}

\section{Akuntansi biaya dan biaya}

Rachmina dan Sari (2016:17) menyatakan bahwa akuntansi biaya adalah proses pencatatan, penggolongan, peringkasan, dan penyajian biaya pembuatan dan penjualan produk atau jasa dengan cara-cara tertentu serta penafsiran informasi biaya. Objek kegiatan akuntansi adalah biaya.

Terkait dengan pengertian biaya, Salman (2016:25) menyatakan tujuan tertentu yang dimaksud dari definisi biaya dapat berupa barang jadi telah laku terjual, telah terjadi penggunaan asset atau pemanfaatan dalam 
bentuk lainnya. Salman (2016:27) menjelaskan bahwa cost digunakan untuk menjelaskan setiap pengeluaran untuk mendapatkan manfaat tersebut belum terjadi atau belum diterima. Konsep cost sering kali diterjemahkan dengan harga pokok, harga perolehan, atau kos. Konsep cost berkaitan dengan cost and benefit analysis. Contoh dari cost adalah harga perlolehan aktiva, pembayaran asuransi dibayar di muka, atau harga pokok produksi.

\section{Objek biaya}

Menurut Salman (2016:280) objek biaya juga dikenal sebagai tujuan biaya. Objek biaya adalah suatu item atau aktifitas yang biayanya diakumulasi dan diukur. Contoh dari objek biaya adalah produk, departemen, pesanan, aktivitas, kontrak, lini produk, divisi, proyek, dan masih banyak lagi contoh lainnya. Untuk dapat mengukur kinerja dengan tepat, pihak manajemen harus mampu memilih objek biaya yang sesuai. Misalnya untuk mengukut efisiensi kerja dari suatu departemen, maka manajemen akan memilih objek biaya departemen.

Oleh karena objek biaya sebagai tempat akhir berkumpulan biaya maka objek biaya berguna untuk menentukan biaya produk (product cost), pengambilan keputusan (decision making), dan evaluasi kerja. Pengukuran biaya tergantung pada pengukuran biaya dari cost object. Penulusuran biaya dari objek biaya bervariasi menurut tingkatannya. Salman (2016: 29) menyatakan cara yang lebih banyak digunakan adalah menggolongkan biaya ke dalam biaya langsung dan biaya tidak langsung.

\section{Sistem Akuntansi Biaya dan Sistem Biaya}

1. Sistem akuntansi biaya

Sistem akuntasi biaya menurut Mulyadi (2016:25) adalah jaringan prosedur yang digunakan untuk mengumpulkan dan menyajikan laporan biaya. Dalam perusahaan manufaktur, sistem akuntansi biaya merupakan jaringan prosedur untuk mengumpulkan dan menyajikan biaya produksi, beban pemasaran, dan beban administrasi umum.

Faktor yang mempengaruhi perancangan sistem akuntansi biaya dalam suatu perusahaan adalah: 
a. Metode costing:

1) full costing, atau

2) variabel costing.

b. Sistem biaya:

1) Sistem biaya standar, atau

2) Sistem biaya historis.

c. Proses produksi:

1) Produksi berdasar pesanan, atau

2) Produksi berdasar proses

2. Sistem biaya

Sistem penentuan biaya merupakan suatu sistem untuk mengalokasikan biaya ke produk, melalui perhitungan biaya. Dalam sistem penentuan biaya ada dasar biaya yang digunakan, yaitu sistem biaya historis dan sistem biaya standar.

a. Sistem biaya historis

Menurut Rachmina dan Sari (2017:17) biaya historis, biaya yang telah terjadi, merupakan biaya sesungguhnya. Salman (2016:50) menyatakan dimana biaya produksi dikumpulkan pada saat terjadinya, tetapi pelaporannya ditunda sampai semua kegiatan produksi selesai dikerjakan.

b. Sistem biaya standar

Biaya standar menurut Rachmina dan Sari (2017:17) yaitu, biaya yang dihitung sebelum proses produksi merupakan perencanaan. Sistem biaya standar oleh Salman (2016:50) yaitu, dimana biaya-biaya produk, operasi, dan proses dihitung berdasarkan unit dan tarif sudah ditetapkan sebelumnnya. Biaya aktual juga dicatat dan dibandingkan dengan biaya yang ditetapkan sebelumnya.

\section{Harga Pokok Produksi}

Rahmani (2018) dalam jurnal consulting Indonesia menyebutkan komponen-komponen dalam harga pokok produksi:

a. Biaya bahan baku, adalah semua biaya yang digunakan untuk membeli bahan baku produksi. 
b. Biaya tenaga kerja langsung, biaya ini merupakan semua biaya yang diperlukan untuk membayar tenaga kerja produksi yang mampu merubah bahan baku menjadi produk jadi.

c. Biaya overhead pabrik, merupakan semua unsur-unsur biaya yang dibutuhkan untuk memproduksi bahan baku menjadi produk jadi siap dijual.

\section{Metode penentuan harga pokok produksi}

Pengertian metode penentuan harga pokok produksi oleh Rachmina dan Sari (2017:18) adalah cara memperhitungkan unsur-unsur biaya ke dalam harga pokok produksi. Dalam memberhitungkan unsur-unsur biaya ke dalam harga pokok produksi, terdapat dua pendekatan yaitu full costing dan variabel costing.

a. Metode full costing

Metode full costing menurut Salman (2016:50) yaitu, penentuan biaya produk dengan cara menjumlahkan semua unsur biaya, baik biaya variabel maupun biaya tetap. Metode ini digunakan untuk penyajian laporan kepada pihak luar.

b. Metode variabel costing

Pernyataan Salman (2016:50) terkait dengan metode variabel costing yaitu, penentuan biaya produk dengan cara memasukkan semua biaya variabel saja. Metode ini tidak dapat digunakan untuk pelaporan kepada pihak luar, tetapi sangat berguna untuk pengambilan keputusan manajemen.

\section{Metode Full Costing}

Mundir (2012) menyatakan bahwa, metode full costing adalah metode penentuan harga pokok produk yang membebankan seluruh biaya produksi kepada produk. Dalam metode full costing, semua unsur biaya produksi baik biaya tetap maupun biaya variabel dihitung sebagai harga pokok produksi. Menurut Rachmina dan Sari (2017:18) full costing merupakan metode penentuan harga pokok produksi yang memperhitungkan semua unsur biaya ke dalam harga pokok produksi yang terdiri dari biaya bahan baku, biaya tenaga kerja langsung dan biaya overhead pabrik (variabel atau tetap). Mulyadi (2015:17) menjelaskan bahwa full costing 
merupakan metode penentuan kos produksi yang memperhitungkan semua unsur biaya produksi ke dalam kos produksi, yang terdiri dari biaya bahan baku, biaya tenaga kerja langsung, dan biaya overhead pabrik, baik yang berperilaku variabel maupun tetap.

\section{METODE PENELITIAN}

\section{Jenis dan Sumber Data}

Jenis data yang digunakan dalam penelitian ini adalah data kualitatif dan Data kuantitatif. Sumber data yang digunakan dalam penelitian ini data primer dan data sekunder. Data primer yaitu data yang diperoleh dari responden melalui kuesioner, kelompok fokus, dan panel, atau juga data hasil wawancara peneliti dengan narasumber. Sedangkan data sekunder yaitu data yang didapat dari catatan, berupa laporan keuangan publikasi perusahaan, laporan pemerintah, artikel, buku-buku sebagai teori, majalah, dan lain sebagainya.

\section{Metode Analisis}

Metode analisis yang digunakan dalam penelitian ini adalah metode analisis deskriptif kualitatif yaitu menjelaskan tentang metode penentuan harga pokok produksi PT. Perkebunan Nusantara XIV (Persero), Pabrik Gula Takalar dengan memperhatikan penentuan harga pokok produksi menggunakan metode full costing dengan unsur unsur harga pokok produksi dalam metode full costing. Mulyadi (2015:18)

Penentuan harga pokok produksi menggunakan metode full costing:

$\begin{array}{lll}\text { Prime cost: } & \text { biaya bahan baku } & \mathrm{xxx} \\ & \text { biaya tenaga kerja langsung } & \mathrm{xxx} \\ \begin{array}{c}\text { Conversion cost: } \text { biaya overhead pabrik tetap } \\ \text { biaya overhead pabrik variabel }\end{array} & \mathrm{xxx} \\ \text { Harga pokok produksi } & \mathrm{xxx}\end{array}$




\section{HASIL PENELITIAN DAN PEMBAHASAN}

\section{Penentuan Harga Pokok Produksi Menurut PT. Perkebunan Nusantara XIV (Persero) Pabrik Gula Takalar}

PT. Perkebunan Nusantara XIV (Persero) Pabrik Gula Takalar merupakan perusahan manufaktur yang memproduksi gula secara massa dan kontinu. Data penjualan Pabrik Gula Takalar pada tahun 2018 menguraikan volume penjualan per ton, harga penjualan gula per ton dan nilai penjualan gula, yaitu sebagai berikut:

1. Volume penjualan gula $13.206,73$ ton

2. Harga penjualan gula $\operatorname{Rp} 9.207 .762 /$ ton

3. Nilai penjualan gula $\mathrm{Rp} 121.604 .429 .750$

Penentuan harga pokok produksi oleh Pabrik Gula Takalar dilakukan dengan mengumpulkan seluruh biaya produksi dan biaya non produksi. Biaya-biaya tersebut diklasifikasikan pada tiap departemen, yaitu departemen pimpinan dan tata usaha, departemen eksploitasi alat pengangkutan, departemen eksploitasi alat pertanian, departemen pembibitan, departemen tebu giling, departemen tebang dan angkut, departemen pabrik, departemen pengolahan, biaya di luar perusahaan, dan penyusutan aktiva tetap.

Penentuan Harga Pokok Produksi PT. Perkebunan Nusantara XIV (Persero) Pabrik Gula Takalar dengan Penentuan Harga Pokok Produksi Metode Full Costing

Berdasarkan penelitian dan analisis Penentuan Harga Pokok Produksi PT. Perkebunan Nusantara XIV (Persero) Pabrik Gula Takalar menunjukkan bahwa dalam penentuan harga pokok produksi pada Pabrik Gula Takalar tidak terdapat selisih jumlah Total Harga pokok produksi dengan penentuan harga pokok produksi dengan metode full costing

Terdapat perbedaan dalam proses pengklasifikasian biaya, baik pada prime cost dan conversion cost, yaitu sebagai berikut: 
Tabel 8: Perbandingan Penentuan Harga Pokok Produksi

\begin{tabular}{|c|c|c|c|}
\hline $\begin{array}{l}\text { Penentuan Harga } \\
\text { Pokok Produksi } \\
\text { Metode Full Costing } \\
\end{array}$ & Jumlah & $\begin{array}{c}\text { Penentuan Harga Pokok } \\
\text { Produksi Menurut Pabrik } \\
\text { Gula Takalar } \\
\end{array}$ & Jumlah \\
\hline \multicolumn{2}{|c|}{ Prime Cost } & \multicolumn{2}{|l|}{ Prime Cost } \\
\hline $\begin{array}{l}\text { Total biaya } \\
\text { bahan baku }\end{array}$ & Rp 23.310.314.942 & $\begin{array}{l}\text { Total biaya departemen } \\
\text { pembibitan }\end{array}$ & $\operatorname{Rp} \quad 3.748 .276 .673$ \\
\hline $\begin{array}{l}\text { Total biaya } \\
\text { tenaga kerja langsung }\end{array}$ & Rp 14.430.824.390 & $\begin{array}{l}\text { Total biaya departemen } \\
\text { tebu giling }\end{array}$ & Rp 19.600.287.785 \\
\hline & & $\begin{array}{l}\text { Total biaya departemen } \\
\text { pengolahan }\end{array}$ & Rp $\quad 9.264 .393 .084$ \\
\hline & & $\begin{array}{l}\text { Total biaya departemen } \\
\text { tebang dan angkut }\end{array}$ & $\mathrm{Rp} \quad 882.346 .924$ \\
\hline & & $\begin{array}{l}\text { Total biaya departemen } \\
\text { pabrik }\end{array}$ & Rp $\quad 4.245 .834 .866$ \\
\hline \multicolumn{2}{|c|}{ Conversion Cost } & \multicolumn{2}{|c|}{ Conversion Cost } \\
\hline $\begin{array}{l}\text { Total biaya overhead } \\
\text { pabrik tetap }\end{array}$ & Rp 16.542.537.181 & $\begin{array}{l}\text { Total biaya } \\
\text { Departemen } \\
\text { Pimpinan dan } \\
\text { tata usaha } \\
\end{array}$ & Rp $\quad 6.440 .085 .327$ \\
\hline \multirow[t]{6}{*}{$\begin{array}{l}\text { Total biaya overhead } \\
\text { pabrik variable }\end{array}$} & Rp 87.121.469.537 & $\begin{array}{l}\text { Total biaya penyusutan } \\
\text { aktiva tetap }\end{array}$ & Rp 10.241.127.907 \\
\hline & & $\begin{array}{l}\text { Total biaya departemen } \\
\text { pembibitan }\end{array}$ & $\mathrm{Rp} \quad 1.704 .361 .881$ \\
\hline & & $\begin{array}{l}\text { Total biaya departemen } \\
\text { tebu giling }\end{array}$ & Rp 27.447 .486 .273 \\
\hline & & $\begin{array}{l}\text { Total biaya departemen } \\
\text { tebang dan angkut }\end{array}$ & $\begin{array}{l}\mathrm{Rp} \\
32.512 .400 .775\end{array}$ \\
\hline & & $\begin{array}{l}\text { Total biaya departemen } \\
\text { pabrik }\end{array}$ & Rp 23.235.056.43 \\
\hline & & $\begin{array}{l}\text { Total biaya departemen } \\
\text { pengolahan }\end{array}$ & $\operatorname{Rp} \quad 2.083 .488 .12$ \\
\hline $\begin{array}{l}\text { Total Harga Pokok } \\
\text { Produksi }\end{array}$ & Rp 141.405.146.05 & $\begin{array}{r}\text { Total Harga Pokok } \\
\text { Produksi }\end{array}$ & Rp 141.405.146.05c \\
\hline
\end{tabular}

Sumber: Data diolah (2019)

Penentuan harga pokok produksi pada PT. Perkebunan Nusantara XIV (Persero) Pabrik Gula Takalar menggunakan metode full costing, namun dengan menjumlahkan seluruh unsur prime cost dan unsur conversion cost yang berada pada tiap departemen. Unsur prime cost diklasifikasikan dari departemen pembibitan, departemen tebu giling, departemen tebang angkut, departemen pabrik dan departemen pengolahan. Unsur conversion cost diklasifikasikan dari departemen pimpinan dan tata usaha, biaya penyusutan aktiva tetap, departemen pembibitan, departemen tebu giling, departemen 
tebang angkut, departemen pabrik dan departemen pengolahan. Dengan total beban produksi pada penentuan harga pokok produksi adalah sebesar Rp 141.405.146.050. Sedangkan Penentuan harga pokok produksi dengan menggunakan metode ful costing mengklasifikasikan biaya ke dalam prime cost, yang terdiri biaya bahan baku dan biaya tenaga kerja langsung dan conversion cost terdiri biaya overhead pabrik tetap dan biaya overhead pabrik variabel, dengan total harga pokok produksi sebesar Rp141.405.146.050

\section{KESIMPULAN}

Berdasarkan hasil penelitian yang dilakukan dapat ditarik kesimpulan bahwa penentuan harga pokok produksi pada PT. Perkebunan Nusantara XIV (Persero) Pabrik Gula Takalar menggunakan metode full costing, dengan jumlah Dengan total beban produksi pada harga pokok produksi adalah sebesar $\operatorname{Rp}$ 141.405.146.050. dan pengklasifikasian biaya seluruh unsur prime cost (Departemen), dan unsur conversion cost (Departemen), unsur biaya tersebut berada pada tiap departemen yang menggabungkan antara prime cost dengan conversion cost. Penentuan harga pokok produksi menggunakan metode full costing yang memperhitungkan seluruh unsur biaya ke dalam harga pokok produksi, yang terdiri dari prime cost dan conversion cost. Penentuan Harga Jumlahnya sama Sebesar Rp 141.405.146.050. Pengklasifikasian biaya dengan metode full costing berdasarkan pada biaya dalam hubungannya dengan fungsi produksi, yaitu biaya bahan baku, biaya tenaga kerja langsung, biaya overhead pabrik tetap dan biaya overhead pabrik variabel.

\section{DAFTAR PUSTAKA}

Goni, Yuvita M. F., dan Afandi Dhullo. 2016. Analisis Perhitungan Harga Pokok Produk di PT. Bangun Wenang Beverages Company Manado. Jurnal EMBA. https://media.neliti.com/media/publications/2933-IDanalisis-perhitungan-harga-pokok-produk-di-pt-bangun-wenang-beve rages-company-ma.pdf. Diakses 21 Oktober 2018. 
Maghfirah, Mifta dan Fazli Syam. 2016. Analisis Perhitungan Harga Pokok Produksi Dengan Penerapan Metode Full Costing pada UMKM Kota Banda Aceh. Jurnal Ilmiah Mahasiswi Ekonomi Akuntansi (JIMEKA). https://media.neliti.com/media/publications/118844833-IDnone.pdf. Diakses 21 Oktober 2018.

Mulyadi. 2015. Akuntansi Biaya Edisi 5. Unit Penerbit dan Percetakan Sekolah Tinggi IImu Manajemen YKPN, Yogyakarta.

Mulyadi. 2016. Sistem Akuntansi Edisi 4. Salemba Empat, Jakarta.

Mundir. 2012. Full Costing Vs Variable Costing. Akuntansi Manaemen. https://manajemenakuntansi.wordpress.com/2012/05/15/full-costingvs-variable-costing/. Diakses 22 Oktober 2018.

Rachmina, Dwi dan Sari Shinta. 2017. Akuntansi Manajemen Teori dan Aplikasi. Polimedia Publishing, Jakarta Selatan.

Rahmani. 2018. Mengenal Lebih Dekat Tentang Penentuan Harga Pokok Produksi. Jurnal Consulting Indonesia. https://www.jurnal.id/e n/blog/2018/mengenal-lebih-dekat-penentuan-harga-pokok-produksi. Diakses 22 Oktober 2018.

Salindeho, Erni. 2015. Analisis Perhitungan Harga Pokok Produksi pada UD. The Sweetets Cookie Manado. Jurnal EMBA. https://media.ne liti.com/media/publications/2429-ID-analisis-perhitungan-harga-poko k-produksi-pada-ud-the-sweetets-cookie-manado.pdf. Diakses 21 Oktober 2018.

Salman, Kautsar. 2016. Akuntansi Biaya Pendekatan Product Costing Edisi Kedua. Indeks, Jakarta Barat.

Sujarweni. 2014. Metodologi Penelitian Lengkap Praktis, dan Mudah Dipahami. Pustaka Baru Press, Yogyakarta.

Widodo. 2017. Metodologi Penelitian Populer dan Praktis. Rajawali Press, Jakarta. 